\title{
The protease-activated receptor-2 agonist induces gastric mucus secretion and mucosal cytoprotection
}

\author{
Atsufumi Kawabata, ${ }^{1}$ Mitsuhiro Kinoshita, ${ }^{1}$ Hiroyuki Nishikawa, ${ }^{2}$ Ryotaro Kuroda, ${ }^{1}$ \\ Minoru Nishida, ${ }^{2}$ Hiromasa Araki, ${ }^{2}$ Naoki Arizono, ${ }^{3}$ Yasuo Oda,${ }^{1}$ and Kazuaki Kakehi ${ }^{1}$
}

${ }^{1}$ Faculty of Pharmaceutical Sciences, Kinki University, Higashi-Osaka, Japan

${ }^{2}$ Research and Development Center, Fuso Pharmaceutical Industries Ltd., Osaka, Japan

${ }^{3}$ Department of Zoology, Kyoto Prefectural University of Medicine, Kyoto, Japan

Address correspondence to: Atsufumi Kawabata, Department of Pathophysiology and Therapeutics, Faculty of Pharmaceutical Sciences, Kinki University, 3-4-1 Kowakae, Higashi-Osaka 577-8502, Japan. Phone: 81-6-6721-2332 ext. 3815; Fax: 81-6-6730-1394; E-mail: kawabata@phar.kindai.ac.jp.

Received for publication July 17, 2000, and accepted in revised form May 1, 2001.

\begin{abstract}
Protease-activated receptor-2 (PAR-2), a receptor activated by trypsin/tryptase, modulates smooth muscle tone and exocrine secretion in the salivary glands and pancreas. Given that PAR-2 is expressed throughout the gastrointestinal tract, we investigated effects of PAR-2 agonists on mucus secretion and gastric mucosal injury in the rat. PAR-2-activating peptides triggered secretion of mucus in the stomach, but not in the duodenum. This mucus secretion was abolished by pretreatment with capsaicin, which stimulates and ablates specific sensory neurons, but it was resistant to cyclo-oxygenase inhibition. In contrast, capsaicin treatment failed to block PAR-2-mediated secretion from the salivary glands. Intravenous calcitonin gene-related peptide (CGRP) and neurokinin A markedly elicited gastric mucus secretion, as did substance $P$ to a lesser extent. Specific antagonists of the CGRP and $\mathrm{NK}_{2}$, but not the $\mathrm{NK}_{1}$, receptors inhibited PAR-2-mediated mucus secretion. Pretreatment with the PAR-2 agonist strongly prevented gastric injury caused by $\mathrm{HCl}$-ethanol or indomethacin. Thus, PAR-2 activation triggers the cytoprotective secretion of gastric mucus by stimulating the release of CGRP and tachykinins from sensory neurons. In contrast, the PAR-2-mediated salivary exocrine secretion appears to be independent of capsaicin-sensitive sensory neurons.
\end{abstract}

J. Clin. Invest. 107:1443-1450 (2001).

\section{Introduction}

Protease-activated receptor-2 (PAR-2) (1), a G protein-coupled receptor, is activated by proteolytic unmasking of the $\mathrm{N}$-terminal extracellular tethered ligand that presumably binds to the extracellular loop 2 of the receptor itself (2-4). Trypsin and mast cell tryptase are considered endogenous activators for PAR-2 $(1,2,5)$. Synthetic peptides based on the receptor-activating sequence of the tethered ligand (e.g., SLIGRL for murine PAR-2) are also capable of activating PAR-2 by direct binding to the receptor (1-5). PAR-2 is involved in a variety of biological events, including modulation of smooth muscle tone (6-9) and of salivary and pancreatic (10-12) exocrine secretion. Recent in vivo studies have indicated that PAR-2 agonists can inhibit bronchoconstriction (13) and improve myocardial ischemia-reperfusion injury (14), predicting their therapeutic application. On the other hand, PAR-2 agonists, when administered locally at high doses, produce inflammation (15-17). Evidence demonstrates that PAR- 2 is present in sensory neurons and triggers release of calcitonin gene-related peptide (CGRP) and substance $P$, resulting in neurogenic inflammation (17). This also predicts that some of the various functions of PAR-2 as described above might be mediated by neuronal mechanisms.
Given that PAR-2 is expressed throughout the gastrointestinal tract, especially by the surface epithelial cells $(1,7,11,18)$, we have focused on PAR-2 as a therapeutic target for diseases related to injury of gastrointestinal mucosa. In the present study, we examined if activation of PAR-2 could trigger mucus secretion in the stomach and duodenum, using SLIGRL-NH $\mathrm{N}_{2}\left(\mathrm{SLp}-\mathrm{NH}_{2}\right)$ and its analogue, $\quad \mathrm{N}$-trans-cynnamoyl-LIGRL-ornithine- $\mathrm{NH}_{2}$ (tcLp- $\mathrm{NH}_{2}$ ), as PAR-2 agonist. The specificity and potency of these peptides in vitro as well as in vivo have been described elsewhere (10, 16, 19-21). Furthermore, we evaluated if the PAR-2 agonist could prevent the gastric injury produced by $\mathrm{HCl} / \mathrm{ethanol}$ or indomethacin in rats. Here we describe, for the first time to our knowledge, that PAR-2 activation induces secretion of mucus by triggering release of endogenous CGRP and tachykinins and also exerts gastric mucosal cytoprotection.

\section{Methods}

Animals and treatment. Male Wistar rats weighing 200-250 g (Japan SLC Inc., Shizuoka, Japan) were used throughout the present experiments. All experimental procedures were approved by the institutional Committee for the Care and Use of Laboratory Animals.

Determination of secretion of gastric and duodenal mucus (mucus glycoprotein) in vivo. We monitored luminal solu- 
ble mucus that originates in insoluble (adherent) mucus (22), as described elsewhere (23). Rats were deprived of food, but not water, for 24 hours before the experiments. Under anesthesia with intraperitoneal urethane at 1.5 $\mathrm{g} / \mathrm{kg}$, the rat was laparotomized, and the pylorus was ligated. Peptides (secretagogues) or vehicle were then administered intravenously (into the femoral vein) or by mouth 1 minute after intravenous or oral administration of amastatin, an aminopeptidase inhibitor, at 2.5 $\mu \mathrm{mol} / \mathrm{kg}$ (administration volume: $1 \mathrm{ml} / \mathrm{kg}$ ). After 30 minutes, the rat was sacrificed by decapitation, and gastric luminal liquid was collected from the excised stomach. In some experiments, the esophagus was also ligated at a level of the thyroid before the agonist challenge in order to completely exclude contamination of gastric liquid with salivary mucus. When secretion of mucus in the duodenum was studied, the common bile-pancreatic duct (at a point close to the duodenum) and the duodenum (at a point $5 \mathrm{~cm}$ distal from the common bile-pancreatic duct) were ligated in addition to the pylorus, and duodenal luminal liquid was collected 30 minutes after the agonist challenge. The amount of gastric or duodenal luminal liquid collected was quantified by weight (milligrams). The amount of mucus (mucus glycoproteins) in the samples obtained from the stomach or duodenum was determined according to a fluorometric method employing galactose oxidase and peroxidase on the basis of the content of $\mathrm{N}$-acetylgalactosaminyl and galactosyl residues in mucin molecules (23). The samples were centrifuged at 10,000 $g$ for 30 minutes, and the supernatant was exposed to ultrafiltration (cut-off molecular weight: 10,000). The large molecular mass fraction remaining on the filter membrane was collected and lyophilized. The materials dissolved in $2 \mathrm{M}$ trifluoroacetic acid $(200 \mu \mathrm{l})$ were hydrolyzed at $100^{\circ} \mathrm{C}$ for 4 hours and then lyophilized. The lyophilized material was dissolved in $0.1 \mathrm{M}$ Tris- $\mathrm{HCl}$ buffer $(200 \mu \mathrm{l})$, and a portion $(50 \mu \mathrm{l})$ was gently mixed with an enzyme solution $(150 \mu \mathrm{l})$ containing galactose oxidase $(2 \mathrm{U} / \mathrm{ml})$, horseradish peroxidase $(1 \mathrm{U} / \mathrm{ml})$, and 3 -( $p$-hydroxyphenyl)propionic acid as a fluorogenic substrate $(1 \mathrm{mM})$, then incubated at $37^{\circ} \mathrm{C}$ for 2 hours. Fluorescence intensity at $405 \mathrm{~nm}$ by irradiating at a $320-\mathrm{nm}$ light was measured. The amount of mucus is represented as content of galactose that was calculated from the calibration curve obtained from fluorometric measurement using standard solution of authentic galactose.

Salivation bioassay and determination of salivary amylase and mucus in vivo. Salivation responses to secretagogues were assessed in the urethane-anesthetized rats after a 24-hour fast, as described previously (10). After the saliva in the animal's oral cavity was removed using an aspirator, the PAR-2 agonist SLp- $\mathrm{NH}_{2}$, in combination with amastatin, was administered intravenously as described above, and the saliva secreted was successively aspirated at 1-minute intervals for 5 minutes and quantified by weight (milligrams). The activity of amylase in the collected saliva was determined by using an assay kit (Amylase B test; Wako Pure Chemicals Industries, Osaka,
Japan). The amount of mucus in the saliva was determined by two distinct methods. One was essentially the same method as described above for the gastrointestinal mucus (23). The other method was based on the amount of sialic acids that are abundant in salivary, but not gastric, mucin molecules (24). Briefly, the collected saliva was hydrolyzed with $0.1 \mathrm{~N} \mathrm{HCl}$, and the amount of $N$-acetylneuraminic acid was determined by reversephase HPLC after derivatization with 1,2-diamino-4,5methylenedioxy-benzene.

Determination of gastric mucosal blood flow. Under urethane anesthesia, gastric mucosal blood flow was measured by a laser Doppler flow meter (ALF-21; Advance Co., Tokyo, Japan) in the rat after a 24-hour fast. A probe (type N; Advance Co.) was placed lightly on the surface of the corpus mucosa through a balancer (ALF-B; Advance Co.). Peptides in combination with amastatin were administered intravenously in the same manner as described above.

Drug administration schedules in inhibition experiments. Diclofenac at $9 \mathrm{mg} / \mathrm{kg}$, a dose that is supramaximal in vivo (25), was administered intravenously 10 minutes before intravenous challenge with the PAR-2 agonist SLp- $\mathrm{NH}_{2}$ at $1 \mu \mathrm{mol} / \mathrm{kg}$ in combination with intravenous amastatin at $2.5 \mu \mathrm{mol} / \mathrm{kg}$. Ablation of sensory nerves was performed by administration of capsaicin as described elsewhere (17). Under pentobarbital anesthesia, capsaicin at 25,50 , and $50 \mathrm{mg} / \mathrm{kg}$ was administered subcutaneously to the rat three times, at 0,6 , and 32 hours, respectively (125 mg/kg in total), and the rat was used for experiments 10 days after the last dose. The $\mathrm{CGRP}_{1}$ receptor antagonist $\mathrm{CGRP}_{8-37}$ at $10 \mathrm{nmol} / \mathrm{kg}$ was administered twice subcutaneously 5 minutes before intravenous amastatin and intravenously $30 \mathrm{sec}-$ onds after intravenous amastatin (30 seconds before intravenous secretagogues). The $\mathrm{NK}_{1}$ receptor antagonist spantide (at $100 \mathrm{nmol} / \mathrm{kg}$ ) or $\mathrm{NK}_{2}$ receptor antagonist GR83074 (at $300 \mathrm{nmol} / \mathrm{kg}$ ) was also administered twice subcutaneously and intravenously in the same manner. The nitric oxide synthase inhibitor $N^{\mathrm{G}}$-nitro-Larginine methyl ester (L-NAME) at $30 \mathrm{mg} / \mathrm{kg}$, a dose capable of inducing marked elevation of blood pressure (26), was administered once intravenously 5 minutes before intravenous amastatin (6 minutes before intravenous $\mathrm{SLp}-\mathrm{NH}_{2}$ ). The doses of $\mathrm{CGRP}_{8-37}$, spantide, GR83074, and L-NAME were decided on the basis of the previous reports (17, 26-29). In all experiments, the control rats received each vehicle for inhibitors or antagonists according to the same schedules.

Evaluation of protective effect of the PAR-2 agonist in rat models for gastric injury. We used two distinct gastric injury models. After a 24-hour fast, gastric lesions were created by oral administration of $1 \mathrm{ml}$ of $60 \%$ ethanol/150 mM $\mathrm{HCl}$ solution in unanesthetized rats without pylorus ligation. In this model, rats received intravenous amastatin at $2.5 \mu \mathrm{mol} / \mathrm{kg}$ and intravenous SLp- $\mathrm{NH}_{2}$ only once, 6 and 5 minutes before the challenge with the injury inducer, respectively, and after 2 hours, were sacrificed for observation of gastric injury. The indomethacin- 
induced gastric lesions were observed 7 hours after subcutaneous administration of indomethacin at $25 \mathrm{mg} / \mathrm{kg}$ (30). In this model, SLp- $\mathrm{NH}_{2}$ was administered intravenously repeatedly, because a single dose of SLp- $\mathrm{NH}_{2}$ at $0.5 \mu \mathrm{mol} / \mathrm{kg}$ produced no effect in the preliminary experiments. The first dose of SLp- $\mathrm{NH}_{2}$ in combination with amastatin was administered intravenously as described above, and subsequently SLp- $\mathrm{NH}_{2}$ was administered intravenously repeatedly at 2 -hour intervals, resulting in four doses in all. For observation of gastric lesions, the stomach excised was opened along the greater curvature, washed, and fixed with $10 \%$ formalin solution. The area of gastric glandular mucosal lesion observed in digital photographs was measured with an image process program (Mac Aspect; Mitani Co., Chiba, Japan), in a blinded evaluation. Lesion area is expressed as a percentage of the total area of the stomach, except for the fundus. For histopathological examination of the gastric lesions induced by $60 \%$ ethanol/150 $\mathrm{mM} \mathrm{HCl}$, paraffin sections were made by a standard method and stained with hematoxylin and eosin.

Peptides and other chemicals employed. PAR-2-related peptides were prepared by a standard solid-phase synthesis procedures in Peptide Synthesis Core Facility, University of Calgary (Calgary, Alberta, Canada) or by us. The concentration, purity, and composition of the peptides were determined by HPLC, mass spectrometry, and quantitative amino acid analysis. Galactose oxidase from Dactylium dendroides, horseradish peroxidase, capsaicin, and L-NAME hydrochloride were purchased from Sigma Chemical Co. (St. Louis, Missouri, USA), and 3-(phydroxyphenyl)propionic acid was obtained from Dojindo Laboratories (Kumamoto, Japan). Amastatin, human CGRP, substance $\mathrm{P}$, neurokinin $\mathrm{A}$, human $\mathrm{CGRP}_{8-37}$, and spantide were purchased from Peptide Institute (Minoh, Japan). Diclofenac sodium salt was from Tokyo Kasei Kogyo Company Ltd. (Tokyo, Japan), and GR83074 was from Bachem AG (Bubendorf, Switzerland). Misoprostol was purchased from Cayman Chemical (Ann Arbor, Michigan, USA). Peptides were dissolved in saline for intravenous administration and in PBS for oral administration. Diclofenac was dissolved in a 5\% bicarbonate $-2.5 \%$ glucose buffer. Capsaicin was suspended in a saline solution containing $10 \%$ ethanol and $10 \%$ Tween80. All other chemicals for intravenous or oral administration were dissolved in saline.

\section{Figure 1}

Effects of PAR-2 agonists on secretion of gastroduodenal mucus and liquid in the rat. SLp- $\mathrm{NH}_{2}$ and tcLp-NH , PAR-2 agonists, $\mathrm{LSp}-\mathrm{NH}_{2}$, a control peptide, misoprostol as a positive control, or vehicle $(\mathrm{V})$ in combination with amastatin at $2.5 \mu \mathrm{mol} / \mathrm{kg}$ were administered intravenously or orally to the rat. (a) Effects of intravenous peptides on gastric mucus and liquid secretion. $n=14$ (vehicle) or 4-5 (secretagogues). (b) Effects of intravenous peptides on gastric mucous and liquid secretion in the rat with an esophagus ligation. $n=4-6$. (c) Effects of oral administration of peptides on gastric mucus secretion. $n=4-6$. (d) Effects of intravenous peptides on duodenal mucus and liquid secretion. $n=4-5$. Data show the mean \pm SEM. ${ }^{A} P<0.05,{ }^{B} P<0.01$ vs. the vehicle-treated group.
Statistics. Data are represented as means with SEM, and statistical significance was analyzed by ANOVA followed by Tukey's multiple-comparison test. $P$ values less than 0.05 were considered significant.

\section{Results}

Effects of PAR-2 agonists on gastric and duodenal mucus secretion in rats in vivo. SLp- $\mathrm{NH}_{2}$ at $0.02-1.0 \mu \mathrm{mol} / \mathrm{kg}$, when administered intravenously in combination with amastatin (an inhibitor of aminopeptidase) at $2.5 \mu \mathrm{mol} / \mathrm{kg}$, which had no effect by itself (data not shown), produced a dose-dependent increase in luminal mucus content in the stomach, without affecting total amount of luminal liquid (Figure 1a). The amount of mucus secreted after intravenous administration of SLp- $\mathrm{NH}_{2}$ at $1 \mu \mathrm{mol} / \mathrm{kg}$ was even greater than that after intravenous administration of misoprostol, a prostaglandin $\mathrm{E}_{1}$ analogue, at a maximally effective dose of $2.6 \mu \mathrm{mol} / \mathrm{kg}$ (Figure 1a). SLp$\mathrm{NH}_{2}$ without amastatin was also capable of triggering
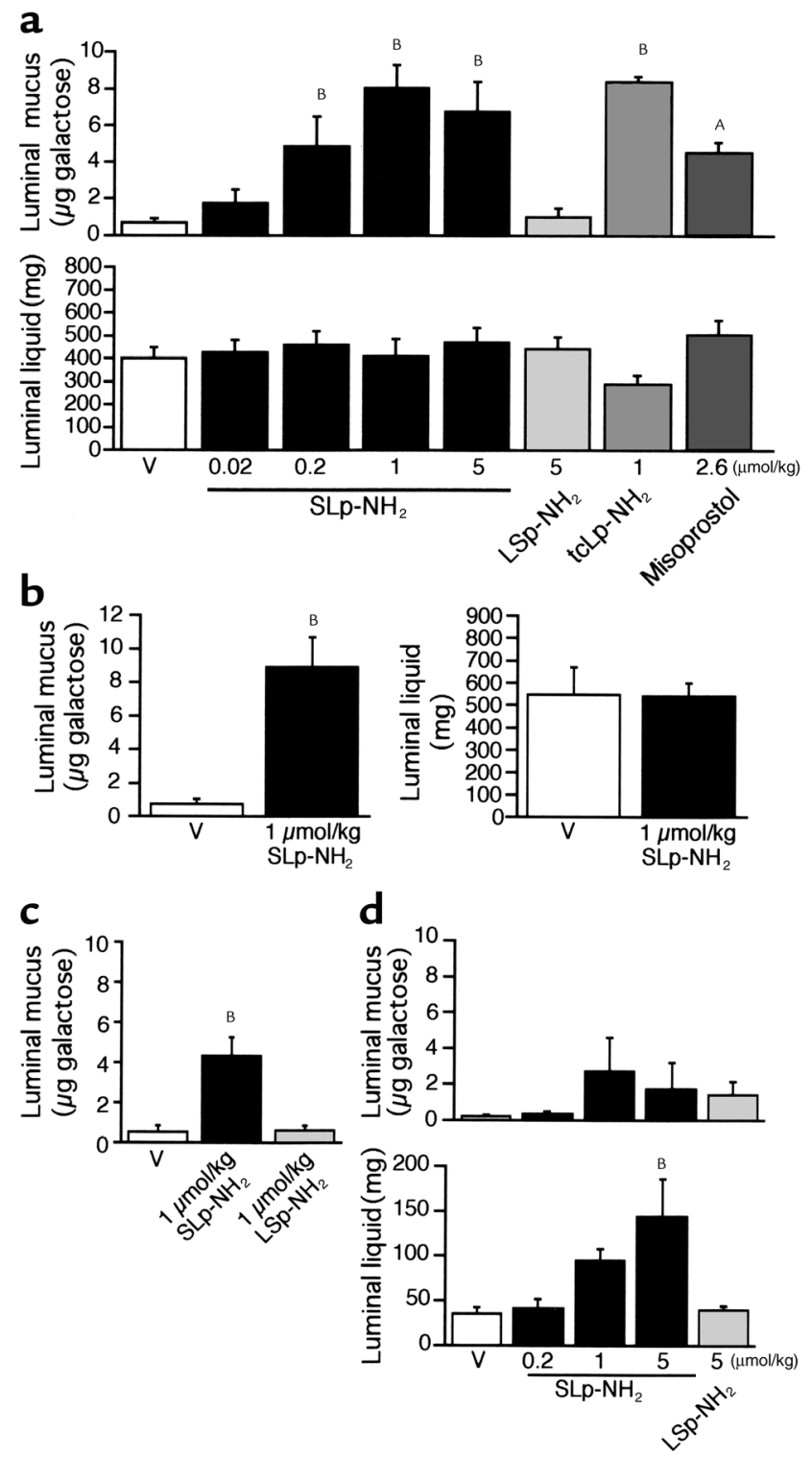

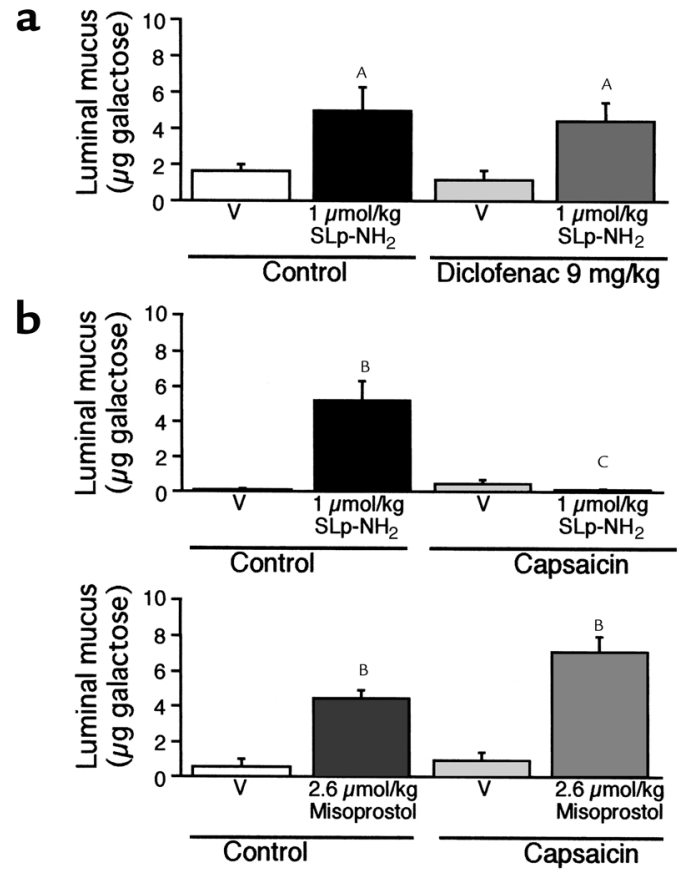

\section{Figure 2}

Effects of diclofenac (a) and capsaicin (b) on the PAR-2-mediated gastric mucus secretion in the rat. Diclofenac was administered intravenously 10 minutes before intravenous $\mathrm{SLp}-\mathrm{NH}_{2}$ plus amastatin at 2.5 $\mu \mathrm{mol} / \mathrm{kg}(\mathbf{a})$. The same dose of SLp- $\mathrm{NH}_{2}$ in combination with amastatin was administered intravenously to the rats that had received repeated doses of capsaicin (b, top panel), as described in Methods. Misoprostol as a positive control was also administered intravenously to capsaicin-treated rats $(\mathbf{b}$, bottom $)$. Data show the mean \pm SEM from 4-6 rats. ${ }^{A} P<0.05,{ }^{B} P<0.01$ vs. the respective vehicle-treated $(V)$ group; ${ }^{C} P<0.01$ vs. the corresponding control group (treated with SLp-NH$H_{2}$ ).

mucus secretion, though it was less effective; the amount (micrograms of galactose) of soluble mucus secreted after intravenous administration of vehicle and SLp- $\mathrm{NH}_{2}$ at 0.2 and $1 \mu \mathrm{mol} / \mathrm{kg}$ alone was $0.15 \pm 0.07,1.80 \pm 0.54$, and $4.79 \pm 1.19(n=4)$, respectively. On the other hand, the PAR-2 inactive control peptide LSIGRL- $\mathrm{NH}_{2}\left(\mathrm{LSp}-\mathrm{NH}_{2}\right)$ at $5 \mu \mathrm{mol} / \mathrm{kg}$ with amastatin failed to mimic the effect of SLp- $\mathrm{NH}_{2}$ (Figure 1a). Another PAR-2 agonist, tcLp- $-\mathrm{NH}_{2}$, at $1 \mu \mathrm{mol} / \mathrm{kg}$ was equipotent as a secretagogue for gastric mucus to SLp- $\mathrm{NH}_{2}$ at the same dose in the presence of amastatin (Figure 1a), in agreement with their relative potency as the PAR-2 agonist in other systems (21). It is also of note that SLP$\mathrm{NH}_{2}$ at the same dose range, with amastatin, had no effect on the basal acid output in the stomach (data not shown). The increased luminal mucus in the stomach produced by systemic administration of the PAR- 2 agonist is not a result of contamination with salivary mucus that is secreted in response to PAR-2 activation $(10,31)$, because the rat with an esophageal ligation also exhibited an increase in gastric mucus following SLp- $\mathrm{NH}_{2}$ plus amastatin (Figure 1b), the magnitude being equivalent to that in the rat with the intact esophagus (Figure 1a). SLp- $\mathrm{NH}_{2}$, but not $\mathrm{LSp}-\mathrm{NH}_{2}$, at 1 $\mu \mathrm{mol} / \mathrm{kg}$ in combination with amastatin at $2.5 \mu \mathrm{mol} / \mathrm{kg}$ was also effective by oral administration in triggering secretion of gastric mucus (Figure 1c).

SLp- $\mathrm{NH}_{2}$ when administered intravenously at 0.2-5.0 $\mu \mathrm{mol} / \mathrm{kg}$ in combination with amastatin at 2.5 $\mu \mathrm{mol} / \mathrm{kg}$ failed to significantly trigger mucus secretion in the duodenum (Figure 1d, upper panel). It is of interest that SLp- $\mathrm{NH}_{2}$, but not $\mathrm{LSp}-\mathrm{NH}_{2}$, elicited an increase in the amount of luminal liquid in the duodenum (Figure $1 \mathrm{~d}$, lower panel).

Effects of diclofenac on the PAR-2-mediated gastric mucus secretion in the rat. We next tested involvement of prostanoids in the gastric mucus secretion evoked by the PAR-2 agonist SLp- $\mathrm{NH}_{2}$. Diclofenac at $9 \mathrm{mg} / \mathrm{kg}$, a supramaximal dose that is enough to almost completely inhibit cyclo-oxygenase within 5 minutes after parenteral administration (25), did not abolish the secretion of gastric mucus due to intravenous SLp- $\mathrm{NH}_{2}$ at $1 \mu \mathrm{mol} / \mathrm{kg}$ plus amastatin (Figure 2a).

Effects of capsaicin on the gastric mucus secretion and salivation exerted by the PAR-2 agonist in the rat. We then evaluated the effect of ablation of sensory nerves by pretreatment with capsaicin on the PAR-2-mediated gastric mucus secretion, considering the most recent evidence that PAR-2 agonists stimulate the primary spinal afferent neurons (17). Capsaicin completely abolished the PAR-2-mediated gastric mucus secretion, while it had no effect on the misoprostol-induced mucus secretion (Figure 2b), strongly suggesting involvement of activation of the capsaicin-sensitive neurons. On the other hand, salivation and secretion of proteins (amylase and mucus) from salivary glands in response to PAR-2 activation that we reported recently $(10,31)$ were not abolished by capsaicin (Table 1).

Effects of CGRP, substance $P$, neurokinin $A$, and their antagonists on the basal or PAR-2-mediated gastric mucus secretion in rats in vivo. We tested if CGRP, substance $P$, and neurokinin A could trigger secretion of gastric mucus in vivo, because these neuropeptides are considered major neurotransmitters in gastric capsaicin-sensitive neurons that

\section{Table 1}

Effects of capsaicin on the PAR-2 agonist-induced salivation and salivary protein secretion in the rat

Treatment

Saliva Amylase

$(\mathrm{mg})$

Control

$71.0 \pm 13.2(9)$

Capsaicin
(IU/g saliva)

$742.2 \pm 73.6(9)$

$984.5 \pm 162.8(10)$
Mucus parameters

$\begin{array}{cc}\text { Galactose }^{\mathrm{A}} & \text { Neu5Ac } \\ (\mu \mathrm{g} / \mathrm{g} \text { saliva }) & (\mu \mathrm{g} / \mathrm{g} \text { saliva })\end{array}$
$(\mu \mathrm{g} / \mathrm{g}$ saliva $)$

$81.8 \pm 27.1$ (9) $\quad 153.2 \pm 20.1(5)$ $69.4 \pm 9.4(10) \quad 164.8 \pm 17.8(5)$
The PAR-2 agonist SLp- $\mathrm{NH}_{2}$ at $1 \mu \mathrm{mol} / \mathrm{kg}$ in combination with amastatin at $2.5 \mu \mathrm{mol} / \mathrm{kg}$ was administered intravenously to the rat that had received repeated administration of capsaicin or vehicle (control). No significant difference was found between the control and capsaicin-treated groups in any parameters. The amount of saliva secreted for 5 minutes after intravenous injection of saline was negligible (less than $3 \mathrm{mg}$ ) in both the control and capsaicin-treated group. Numbers in parentheses show the number of rats. ${ }^{\mathrm{A}} \mathrm{N}$-acetylgalactosamine/galactose referred to as galactose. Neu5Ac, $N$-acetyl neuraminic acid. 


\section{Figure 3}

Effect of CGRP, substance $P$, neurokinin $A$ (NKA), and their antagonists on the basal and PAR2-mediated gastric mucus secretion in the rat. (a) CGRP, substance $P$, or NKA, in combination with amastatin at $2.5 \mu \mathrm{mol} / \mathrm{kg}$, was administered intravenously to the rat. ${ }^{A} P<0.05,{ }^{B} P<0.01$ vs. the vehicle-treated $(V)$ group. Data show the mean \pm SEM from 4-7 rats. (b) Effects of the $\mathrm{CGRP}_{1}$ receptor antagonist $\mathrm{CGRP}_{8-37}$ (10 $\mathrm{nmol} / \mathrm{kg} \times 2$, subcutaneously and intravenously), the $\mathrm{NK}_{1}$ receptor antagonist spantide (100 $\mathrm{nmol} / \mathrm{kg} \times 2$, subcutaneously and intravenously), or the $\mathrm{NK}_{2}$ receptor antagonist GR83074 (300 $\mathrm{nmol} / \mathrm{kg} \times 2$, subcutaneously and intravenously) on the gastric mucus secretion due to intravenous administration of CGRP at $0.28 \mathrm{nmol} / \mathrm{kg}$, substance $P$ at $10 \mathrm{nmol} / \mathrm{kg}$, or NKA at $0.01 \mathrm{nmol} / \mathrm{kg}$. ${ }^{A} P<0.05,{ }^{B} P<0.01$ vs. $V$ plus $V ;{ }^{C} P<0.05$, $\mathrm{D} P<0.01$ vs. $V$ plus each agonist. $n=5-9$. (c) Synergistic effect of CGRP and NKA on mucus secretion. CGRP and/or NKA at subeffective doses were administered intravenously in combination with amastatin. ${ }^{A} P<0.01$ vs. $V ; n=5-6$. (d) Effects of $\mathrm{CGRP}_{8-37}$, spantide, or GR83074, administered as described above, on the gastric mucus secretion due to intravenous administration of the PAR-2 agonist SLp- $\mathrm{NH}_{2}$ at $1 \mu \mathrm{mol} / \mathrm{kg}$ in combination with amastatin at $2.5 \mu \mathrm{mol} / \mathrm{kg}$. ${ }^{A} P<0.01$ vs. $V$ plus $V ;{ }^{B} P<0.01$ vs. $V$ plus SLp-NH $\mathrm{NH}_{2} n=4-6$ rats. a
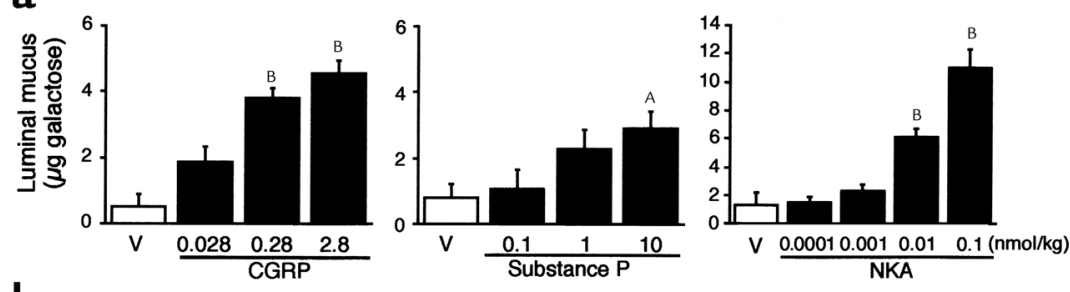

b
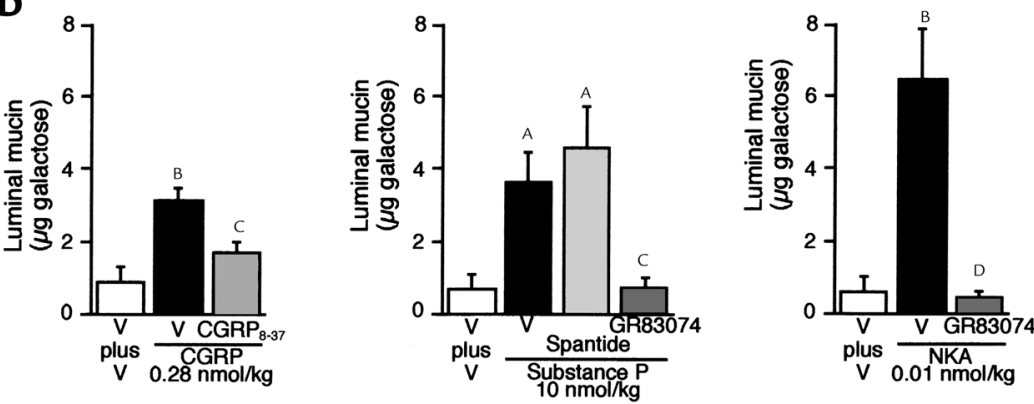

C

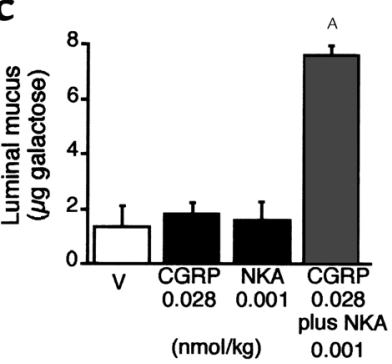

d

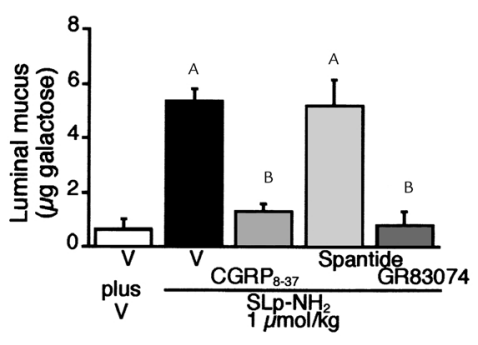

play an important role in mucosal protection $(32,33)$ and may be stimulated by the PAR-2 agonist as described above. CGRP, administered intravenously in a dose range of $0.028-2.8 \mathrm{nmol} / \mathrm{kg}$, in combination with amastatin, remarkably triggered secretion of gastric mucus in a dosedependent manner (Figure 3a, left panel). A larger dose, $28 \mathrm{nmol} / \mathrm{kg}$, of CGRP was also tested, but failed to induce additional effect (data not shown). Substance P at $0.1-10.0 \mathrm{nmol} / \mathrm{kg}$ also elicited secretion of mucus in a similar fashion (Figure 3a, middle panel), although a larger dose $(100 \mathrm{nmol} / \mathrm{kg}$ ) could not elicit further effect (data not shown). Neurokinin A at very low doses (0.001-0.1 $\mathrm{nmol} / \mathrm{kg}$ ) produced very strong effect in stimulating mucus secretion (Figure 3a, right panel). Larger doses of neurokinin A than $0.1 \mathrm{nmol} / \mathrm{kg}$ evoked no additional effect (data not shown). Thus, the order of the potency of these peptides was neurokinin $A>C G R P>$ substance $P$. We then examined the effects of some receptor antagonists for the neuropeptides on the evoked gastric mucus secretion. The effects of CGRP at $0.28 \mathrm{nmol} / \mathrm{kg}$ and neurokinin $\mathrm{A}$ at $0.01 \mathrm{nmol} / \mathrm{kg}$ were inhibited by the $\mathrm{CGRP}_{1}$ receptor antagonist $\mathrm{CGRP}_{8-37}$ at $10 \mathrm{nmol} / \mathrm{kg}$ and by $\mathrm{NK}_{2}$ receptor-specific antagonist GR83074 at $300 \mathrm{nmol} / \mathrm{kg}$, respectively. The substance P-evoked $(10 \mathrm{nmol} / \mathrm{kg})$ mucus secretion was resistant to the $\mathrm{NK}_{1}$ receptor preferential antagonist spantide at $100 \mathrm{nmol} / \mathrm{kg}$, but completely blocked by GR83084 (Figure 3b). Thus, it appears that CGRP exerts effect via CGRP ${ }_{1}$ receptors, and both neurokinin $\mathrm{A}$ and substance $\mathrm{P}$ produce effects via $\mathrm{NK}_{2}$, but not $\mathrm{NK}_{1}$, receptors. Subeffective doses of CGRP and neurokinin A $(0.028$ and $0.001 \mathrm{nmol} / \mathrm{kg}$, respectively), when coadministered, synergistically produced marked secretion of gastric mucus (Figure 3c). The secretion of mucus exerted by the PAR-2 agonist SLP- $\mathrm{NH}_{2}$ at 1 $\mu \mathrm{mol} / \mathrm{kg}$ in combination with amastatin was inhibited by $\mathrm{CGRP}_{8-37}$ and GR83084, but not by spantide, indicating involvement of CGRP ${ }_{1}$ and $\mathrm{NK}_{2}$ receptors, but not $\mathrm{NK}_{1}$ receptors (Figure $3 \mathrm{~d}$ ).

Effect of the PAR-2 agonist on gastric mucosal blood flow in the rat. The PAR-2 agonist SLP-NH peptide $\mathrm{LSp}-\mathrm{NH}_{2}$, when administered intravenously at $1 \mu \mathrm{mol} / \mathrm{kg}$ in combination with amastatin, produced a

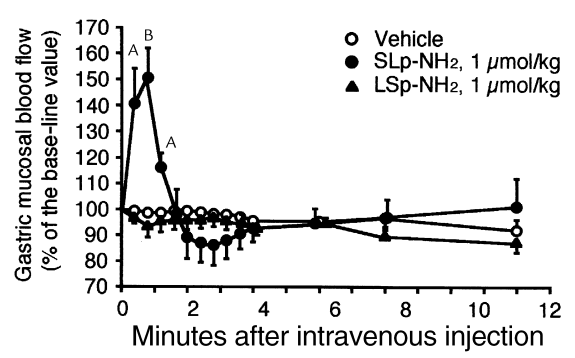

Figure 4

Effect of the PAR-2-related peptides on gastric mucosal blood flow in the rat. The PAR-2 agonist SLp- $\mathrm{NH}_{2}$, the control peptide $\mathrm{LSp}-\mathrm{NH}_{2}$, or vehicle in combination with amastatin at $2.5 \mu \mathrm{mol} / \mathrm{kg}$ was administered intravenously to the rat. Data show the mean \pm SEM from eight rats. ${ }^{A} P<0.05,{ }^{B} P<0.01$ vs. the vehicle-treated group. 


\section{Figure 5}

Protective effect of the PAR-2 agonist SLp- $\mathrm{NH}_{2}$ in two distinct gastric injury models. ( $\mathbf{a}$ and $\mathbf{b}$ ) Typical microphotographs of the gastric lesions caused by $150 \mathrm{mM} \mathrm{HCl} / 60 \%$ ethanol in the rats treated with intravenous vehicle (a) and intravenous SLp- $\mathrm{NH}_{2}$ at $0.5 \mu \mathrm{mol} / \mathrm{kg}$ in combination with amastatin at $2.5 \mu \mathrm{mol} / \mathrm{kg}(\mathbf{b})$. In the vehicle-treated rats, the upper three-fourths of the mucosa reveals necrosis with marked desquamation of gastric gland lining cells, and microhemorrhage at the base of the lesion (arrows). In the SLp- $\mathrm{NH}_{2}$-treated rats, only a superficial layer (arrowheads) of the mucosa shows necrosis and epithelial cell desquamation, while middle and deep layers of the mucosa are intact. Hematoxylin and eosin stain. Bars, $100 \mu \mathrm{m}$. (c) Dose-related effect of SLp- $\mathrm{NH}_{2}$ and its inhibition by capsaicin treatment in the gastric injury model induced by $150 \mathrm{mM} \mathrm{HCl} / 60 \%$ ethanol. Data show the mean \pm SEM from 11 (vehicle) or five to eight $\left(\mathrm{SLp}-\mathrm{NH}_{2}\right)$ rats. (d) Dose-related effect of repeated doses of SLp- $\mathrm{NH}_{2}$ in the gastric injury model induced by indomethacin. $n=5-6$. ${ }^{A} P<0.05,{ }^{B} P<0.01$ vs. vehicle $(V)$. NS, not significant.

rapid and transient increase in the gastric mucosal blood flow, an effect peaking after 1 minute and disappearing after 2 minutes (Figure 4). This PAR-2-mediated effect was not significantly reduced by the CGRP $_{1}$ receptor antagonist $\mathrm{CGRP}_{8-37}(10 \mathrm{nmol} / \mathrm{kg}$, administered two times, subcutaneously and intravenously) or by the nitric oxide synthase inhibitor L-NAME $(30$ $\mathrm{mg} / \mathrm{kg}$, intravenously): the maximal blood flow (percentage of the baseline value) after intravenous SLP$\mathrm{NH}_{2}$ was $172.4 \pm 10.0,172.3 \pm 24.4$, and $153.7 \pm 18.8$ in the control group and in the groups treated with $\mathrm{CGRP}_{8-37}$ and with L-NAME, respectively $(n=3)$. It was also confirmed that the PAR-2-mediated increase in blood flow was resistant to GR83074 (300 nmol/kg, administered two times, subcutaneously and intravenously): the maximal value (percentage) following SLp- $\mathrm{NH}_{2}$ was $151.3 \pm 8.8$ and $175.3 \pm 10.2$ in the control and GR83074-treated groups, respectively $(n=3)$. Protective effects of the PAR-2 agonist on the gastric injury produced by $\mathrm{HCl} /$ ethanol or indomethacin in rats. Finally, we examined the protective effect of the PAR-2 agonist on two types of rat models for gastric injury (Figure 5, a and b; Figure 5c, left; and Figure 5d). SLp- $\mathrm{NH}_{2}$, when preadministered intravenously at $0.02,0.2$, and 0.5 $\mu \mathrm{mol} / \mathrm{kg}$, dose dependently reduced the gastric mucosal lesion produced by $60 \%$ ethanol $/ 150 \mathrm{mM} \mathrm{HCl}$ (Figure $5 c$, left). Microscopic observations of the stomach from the control rats revealed relatively well-demarcated necrotic lesions in the upper one-half to three-fourths of the mucosa, along with microhemorrhage at the base of lesions, and also showed eosinophil infiltration in the deep layer of the mucosa and submucosal tissue (Figure $5 \mathrm{a})$. On the other hand, the sections of the stomach from the rat treated with SLp- $\mathrm{NH}_{2}$ at $0.5 \mu \mathrm{mol} / \mathrm{kg}$ showed only sheetlike desquamation of surface epithelium or necrosis in the superficial layer of the mucosa, with intact gastric glands in the middle and deep layers, and revealed no or negligible hemorrhage (Figure $5 b$ ). It is of note that the effect of the largest dose $(1 \mu \mathrm{mol} / \mathrm{kg})$ of SLp- $-\mathrm{NH}_{2}$ was less than that of $0.5 \mu \mathrm{mol} / \mathrm{kg}$ and
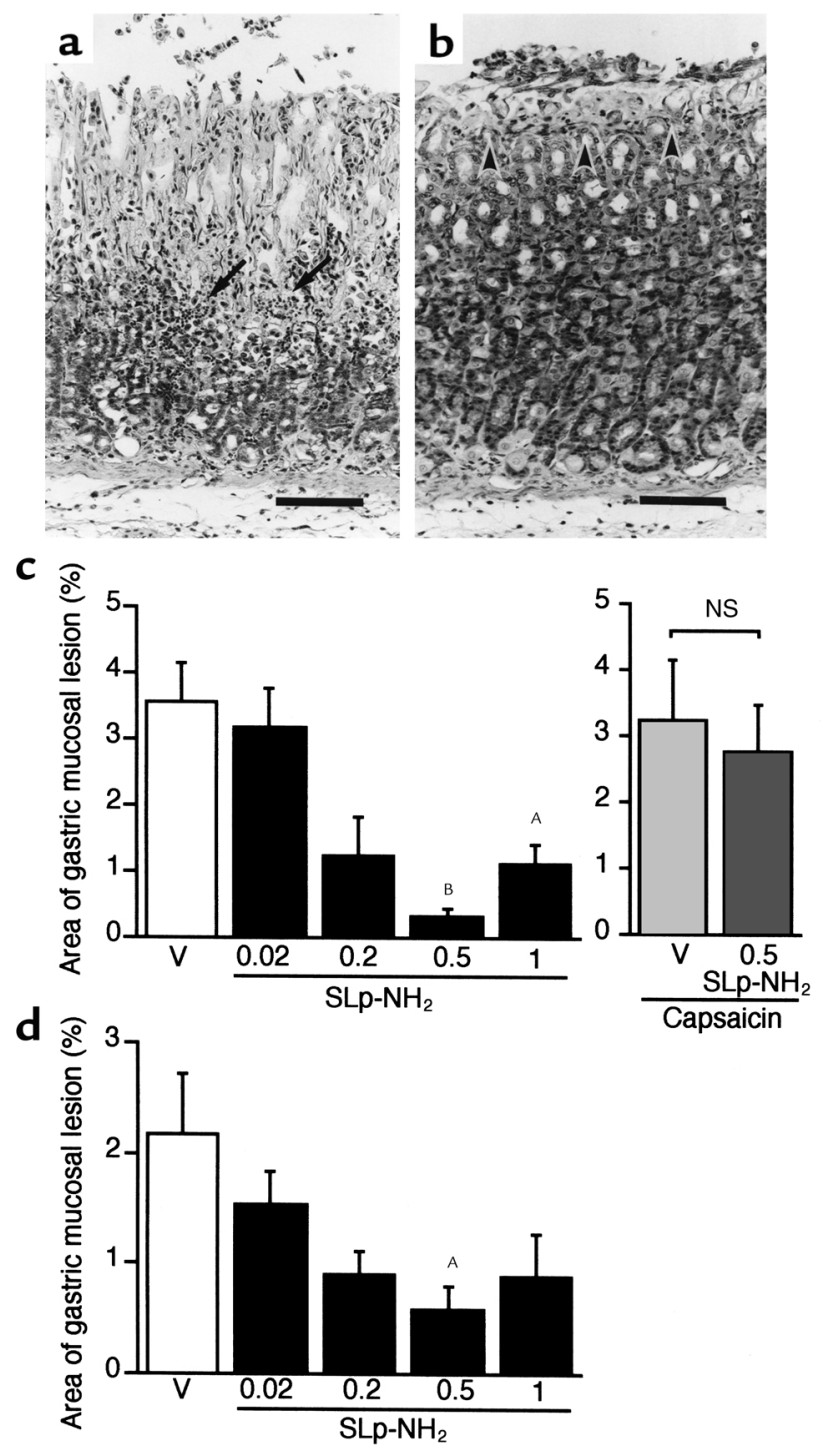

equivalent to that of $0.2 \mu \mathrm{mol} / \mathrm{kg}$ (Figure $5 \mathrm{c}$, left), being a little distinct from the dose-related effect on mucus secretion (see Figure 1). The protective effect of SLP$\mathrm{NH}_{2}$ at $0.5 \mu \mathrm{mol} / \mathrm{kg}$ was abolished by pretreatment with capsaicin (Figure 5c, right), indicating involvement of sensory neurons. Furthermore, $\mathrm{SLp}-\mathrm{NH}_{2}$, when administered four times at $0.02,0.2$, and $0.5 \mu \mathrm{mol} / \mathrm{kg}$, reduced the indomethacin-created gastric lesions in a dosedependent manner (Figure 5d). Another PAR-2 agonist, tcLp- $\mathrm{NH}_{2}$, was not tested for the protective effect in the gastric injury models, because it was highly toxic at doses larger than $1 \mu \mathrm{mol} / \mathrm{kg}$, possibly by mechanisms independent of PAR-2; the mortality in rats and mice treated with intravenous tcLp- $\mathrm{NH}_{2}$ at 5 and 15 $\mu \mathrm{mol} / \mathrm{kg}$, respectively, was $100 \%$ (five rats or mice out of five), while SLp- $\mathrm{NH}_{2}$, even at $50 \mu \mathrm{mol} / \mathrm{kg}$, was not lethal (no rats or mice out of ten died).

\section{Discussion}

The present study, for the first time to our knowledge, demonstrates that the PAR-2 agonists administered par- 
enterally or orally trigger secretion of gastric, but not duodenal, mucus through release of endogenous CGRP and tachykinins, being independent of prostanoid formation. Our data also provide evidence that exogenously applied CGRP, as well as tachykinins by themselves, are capable of triggering secretion of gastric mucus. In contrast, our results reveal that the PAR-2-mediated salivary exocrine secretion is independent of capsaicin-sensitive sensory neurons, implying the complexity of the PAR-2-mediated modulation of exocrine secretion. Finally, our data show that the PAR-2 agonist exerts strong gastric mucosal cytoprotection.

Recent studies have suggested that PAR-2 triggers secretion of saliva including amylase and mucin in salivary glands $(10,31)$ and of pancreatic juice including amylase in the pancreas (10-12). The PAR-2-mediated gastric mucus secretion observed in the present study supports our previous hypothesis that PAR-2 may play a general or key role in regulation of digestive exocrine secretion (10). It is clear from our data that the increase in gastric mucus content following systemic administration of the PAR-2 agonist is not due to contamination with salivary mucus. The gastric mucus secretion produced by orally administered SLp- $\mathrm{NH}_{2}$ (Figure 1c) is attributable to direct activation of PAR-2 present in gastric luminal surface or neighboring regions, as in the intestinal surface $(7,11$, 18), because salivation that occurred following parenteral administration of SLp- $\mathrm{NH}_{2}$, as reported previously (10), was not seen after its oral administration (data not shown), indicating little or no significant absorption of the peptide into blood circulation. This may be beneficial for clinical application of PAR-2 agonists as gastric cytoprotective agents in the future, since side effects due to systemic distribution of the drugs could be avoided.

There is evidence that PAR-2 agonists, like prostaglandins, are proinflammatory (15-17), leading to a dilemma in the therapeutic use of PAR-2 agonists (34). The relatively decreased protective effect of the PAR-2 agonist SLp- $\mathrm{NH}_{2}$ at the maximal dose employed (1 $\mu \mathrm{mol} / \mathrm{kg}$ ) in the two gastric injury models studied (Figure 5 , c and d) might reflect its proinflammatory property. Long-lasting severe neurogenic inflammation in the rat hindpaw is induced by local (subplantar) injection of SLp- $\mathrm{NH}_{2}$ at a very high dose, $500 \mu \mathrm{g} / \mathrm{paw}(16,17)$. The effective dose range of SLp- $\mathrm{NH}_{2}$ for systemic (intravenous) administration, either alone or in combination with amastatin, in our study was $0.2-1.0 \mu \mathrm{mol} / \mathrm{kg}$ (130-650 $\mu \mathrm{g} / \mathrm{kg}$; approximately $32.5-162.5 \mu \mathrm{g} / \mathrm{rat}$ ), which would be too low to induce such serious inflammation after systemic distribution. Although the different effects of PAR-2 agonists could also be related to tissue, species, or models studied, we believe that PAR-2 could be a novel target for development of gastric mucosal protective agents. Nonpeptide PAR-2 agonists that are resistant to enzymatic metabolism remain to be developed. It is also noteworthy that the PAR-2 agonist SLIGRL or SLp- $\mathrm{NH}_{2}$ do not induce contraction of pregnant (35) and nonpregnant (our unpublished data) rat myometrium that is one of the most serious side effects of prostaglandin $\mathrm{E}$ analogues widely used as mucosal protective agents for treatment of gastroduodenal ulcer. Our data strongly suggest that the PAR-2 agonist stimulates the capsaicin-sensitive neurons, and CGRP and tachykinins released upon stimulation trigger secretion of mucus and exert gastric mucosal protection. Our study provides evidence that $\mathrm{CGRP}_{1}$ and $\mathrm{NK}_{2}$, but not $\mathrm{NK}_{1}$, receptors mediate the PAR-2-mediated gastric mucus secretion. The role of substance $\mathrm{P}$ (an endogenous $\mathrm{NK}_{1}{ }^{-}$ preferential agonist with some $\mathrm{NK}_{2}$ activity) in mucin secretion appears to be minor in terms of the effective dose range, as compared with that of CGRP and neurokinin A, an endogenous $\mathrm{NK}_{2}$-preferential agonist. It is also of note that CGRP and neurokinin A synergistically increased mucus secretion. The gastric mucosal protection exerted by CGRP, which has been well described, is considered to be attributable to the suppressed acid output and/or increased mucosal blood flow caused by CGRP $(32,33,36$, 37). Taken together with the most recent study indicating modulation by CGRP of mucin synthesis in rat gastric mucosa (38), our results would add stimulation of mucus secretion to the list of the potential mechanisms underlying the gastric mucosal protection due to CGRP. The finding that the PAR-2 agonist caused a temporary increase in gastric mucosal blood flow in a manner independent of CGRP might imply that PAR-2 is not necessarily distributed to all CGRP neurons present in the gastric mucosa. In other words, CGRP neurons regulating gastric mucosal blood vessels might not express sufficient amount of PAR-2. Considering its rapid disappearance, the PAR2-mediated blood flow increase may play only a minor role in the gastric mucosal cytoprotection exerted by the PAR-2 agonist. It is a little surprising that the PAR2 -mediated transient blood flow increase in the gastric mucosa was not blocked even by the nitric oxide synthase inhibitor L-NAME, because PAR-2 elicits release of endothelial nitric oxide, leading to vascular relaxation in vitro (6). However, this is consistent with the previous evidence that the transient hypotension following intravenous bolus injection of SLp- $\mathrm{NH}_{2}$ is reduced only partially by L-NAME in vivo (26). Involvement of other mechanisms or substances, including endotheliumderived hyperpolarization factor, remains to be tested. It is clear that the gastric mucosal protection exerted by PAR-2 is independent of prostanoid formation that may mediate some of effects of PAR-2 agonists in other systems $(6,13,18)$, considering that the PAR-2 agonist produced diclofenac-resistant mucus secretion and attenuated the indomethacin-created gastric injury in the present study.

Interestingly, the PAR-2-mediated salivation and secretion of amylase or mucus from the salivary glands were resistant to pretreatment with capsaicin in vivo in the present study, although substance $P$, which the capsaicin-sensitive neurons abundantly contain in general, is known to be one of potent secretagogues in the salivary glands (39), thereby implying involvement of mechanisms distinct from those in the gastric mucosa. The detailed mechanisms responsible for the PAR-2-mediated salivary exocrine secretion are still largely open to 
question, although our recent paper has suggested involvement of tyrosine kinase (31).

That the PAR-2 agonist in combination with amastatin was incapable of triggering mucus secretion in the duodenum is against our expectation, because Kong et al. (18) have shown that activation of PAR-2 produces secretion of prostaglandin $E_{2}$ in isolated rat jejunum, which is a well-known secretagogue for gastrointestinal mucus. Nevertheless, the PAR-2 agonist elicited an increase in the amount of luminal liquid in the duodenum. This might be interpreted by recent evidence that a PAR-2-like receptor activated by SLp- $\mathrm{NH}_{2}$ modulates intestinal ion transport via a prostanoid-mediated mechanism (20). Thus, the action of PAR-2 agonists in the stomach and duodenum is greatly distinct.

Endogenous tryptase in mast cells and also coagulation factors VII and X in blood stream $(40,41)$, novel candidates for endogenous PAR-2 activators, might become activated and/or accessible to PAR-2 present on the sensory neurons in the stomach during inflammation or tissue injury and trigger release of CGRP and tachykinins by activating PAR-2, resulting in secretion of mucus and mucosal protection. Trypsin that is now known to be expressed in a wide variety of tissues (13, 42 ), including epithelial cells in the esophagogastrointestinal tract (42), could also be a candidate for endogenous activators of PAR-2 in the stomach, as described recently (34). In conclusion, the present results imply a novel protective role for the inflammatory proteases-PAR-2 system in the gastric mucosa.

1. Nystedt, S., Emilsson, K., Wahlestedt, C., and Sundelin, J. 1994. Molecular cloning of a potential proteinase activated receptor. Proc. Natl. Acad. Sci. USA. 91:9208-9212

2. Kawabata, A., and Kuroda, R. 2000. Protease-activated receptor (PAR), a novel family of $G$ protein-coupled seven trans-membrane domain receptors: activation mechanisms and physiological roles. Jpn. J. Pharmacol. 82:171-174

3. Lerner, D.J., Chen, M., Tram, T., and Coughlin, S.R. 1996. Agonist recognition by protease-activated receptor 2 and thrombin receptor. J. Biol. Chem. 271:13943-13947.

4. Al-Ani, B., Saifeddine, M., Kawabata, A., and Hollenberg, M.D. 1999. Proteinase activated receptor 2: role of extracellular loop 2 for ligand-mediated activation. Br. J. Pharmacol. 128:1105-1113.

5. Molino, M., et al. 1997. Interactions of mast cell tryptase with thrombin receptors and PAR-2. J. Biol. Chem. 272:4043-4049.

6. Saifeddine, M., Al-Ani, B., Cheng, C.-H., Wang, L., and Hollenberg, M.D 1996. Rat proteinase-activated receptor-2 (PAR-2): cDNA sequence and activity of receptor-derived peptides in gastric and vascular tissue. Br. J. Pharmacol. 118:521-530.

7. Corvera, C.U., et al. 1997. Mast cell tryptase regulates rat colonic myocytes through proteinase-activated receptor 2. J. Clin. Invest. 100:1383-1393.

8. Kawabata, A., Kuroda, R., Nishikawa, H., and Kawai, K. 1999. Modulation by protease-activated receptors of the rat duodenal motility in vitro: possible mechanisms underlying the evoked contraction and relaxation. Br. J. Pharmacol. 128:865-872.

9. Cocks, T.M., Sozzi, V., Moffatt, J.D., and Selemidis, S. 1999. Protease-activated receptors mediate apamin-sensitive relaxation of mouse and guinea pig gastrointestinal smooth muscle. Gastroenterology. 116:586-592.

10. Kawabata, A., Nishikawa, H., Kuroda, R., Kawai, K., and Hollenberg, M.D. 2000. Proteinase-activated receptor-2 (PAR-2): regulation of salivary and pancreatic exocrine secretion in vivo in rats and mice. Br. J. Pharmacol. 129:1627-1632.

11. Bohm, S.K., et al. 1996. Molecular cloning, expression and potential functions of the human proteinase-activated receptor-2. Biochem. J. 314:1009-1016.

12. Nguyen, T.D., et al. 1999. Trypsin activates pancreatic duct epithelial cell ion channels through proteinase-activated receptor-2.J. Clin. Invest. 103:261-269.

13. Cocks, T.M., et al. 1999. A protective role for protease-activated receptors in the airways. Nature. 398:156-160.

14. Napoli, C., et al. 2000. Protease-activated receptor-2 modulates myocardial ischemia-reperfusion injury in the rat heart. Proc. Natl. Acad. Sci. USA. 97:3678-3683.

15. Kawabata, A., Kuroda, R., Minami, T., Kataoka, K., and Taneda, M. 1998. Increased vascular permeability by a specific agonist of protease-activated receptor-2 in rat hindpaw. Br. J. Pharmacol. 125:419-422.

16. Vergnolle, N., Hollenberg, M.D., Sharkey, K.A., and Wallace, J.L. 1999. Characterization of the inflammatory response to proteinase-activated receptor2 (PAR-2)-activating peptides in the rat paw. Br.J. Pharmacol. 127:1083-1090.

17. Steinhoff, M., et al. 2000. Agonists of proteinase-activated receptor 2 induce inflammation by a neurogenic mechanism. Nat. Med. 6:151-158.

18. Kong, W., et al. 1997. Luminal trypsin may regulate enterocytes through proteinase-activated receptor 2. Proc. Natl. Acad. Sci. USA. 94:8884-8889.

19. Kawabata, A., Saifeddine, M., Al-Ani, B., Leblond, L., and Hollenberg, M.D. 1999. Evaluation of proteinase-activated receptor- $1\left(\mathrm{PAR}_{1}\right)$ agonists and antagonists using a cultured cell receptor desensitization assay: activation of $\mathrm{PAR}_{2}$ by $\mathrm{PAR}_{1}$ targeted ligands. J. Pharmacol. Exp. Ther. 228:358-370.

20. Vergnolle, N., et al. 1998. Proteinase-activated receptor $2\left(\mathrm{PAR}_{2}\right)$-activating peptides: identification of a receptor distinct from $\mathrm{PAR}_{2}$ that regulates intestinal transport. Proc. Natl. Acad. Sci. USA. 95:7766-7771.

21. Al-Ani, B., et al. 1999. Proteinase-activated receptor-2 ( $\left.\mathrm{PAR}_{2}\right)$ : development of a ligand-binding assay correlating with activation of $\mathrm{PAR}_{2}$ by $\mathrm{PAR}_{1}$ - and $\mathrm{PAR}_{2}$-derived peptide ligands. J. Pharmacol. Exp. Ther. 290:753-760.

22. Allen, A., and Carroll, N.J.H. 1985. Adherent and soluble mucus in the stomach and duodenum. Dig. Dis. Sci. 30(Suppl.):55S-62S.

23. Kinoshita, M., et al. 2000. Fluorometric determination of mucin-type glycoproteins by the galactose oxidase-peroxidase method. Anal. Biochem. 284:87-92.

24. Kawabata, A., et al. 2000. Determination of mucin in salivary glands using sialic acids as the marker by high-performance liquid chromatography with fluorometric detection. Anal. Biochem. 283:119-121.

25. Giuliano, F., and Warner, T.D. 1999. Ex vivo assay to determine the cyclooxygenase selectivity of non-steroidal anti-inflammatory drugs. Br. J. Pharmacol. 126:1824-1830.

26. Moore, P.K., Oluyomi, A.O., Babbedge, R.C., Wallace, P., and Hart, S.L. 1991. $\mathrm{L}-\mathrm{N}^{\mathrm{G}}$-nitro arginine methyl ester exhibits antinociceptive activity in the mouse. Br. J. Pharmacol. 102:198-202

27. Cheung, W.-M., Andrade-Gordon, P., Derian, C.K., and Damiano, B.P. 1998. Receptor-activating peptides distinguish thrombin receptor (PAR-1) and protease activated receptor 2 (PAR-2) mediated hemodynamic responses in vivo. Can. J. Physiol. Pharmacol. 76:16-25.

28. Matsumoto, J., Takeuchi, K., and Okabe, S. 1991. Characterization of gastric mucosal blood flow response induced by intragastric capsaicin in rats. Jpn. J. Pharmacol. 57:205-213.

29. McElroy, A.B., et al. 1992. Highly potent and selective heptapeptide antagonists of the neurokinin NK-2 receptor. J. Med. Chem. 35:2582-2591.

30. Nishida, A., et al. 1994. YM022 [(R)-1-[2,3-dihydro-1-(2'-methylphenacyl)2-oxo-5-phenyl- 1H-1,4-benzodiazepin-3-yl]-3-(3-methylphenyl)urea], a potent and selective gastrin/cholecystokinin-B receptor antagonist, prevents gastric and duodenal lesions in rats. J. Pharmacol. Exp. Ther. 270:1256-1261.

31. Kawabata, A., et al. 2000. Activation of protease-activated receptor-2 triggers mucin secretion in the rat sublingual gland. Biochem. Biophys. Res. Commun. 270:298-302.

32. Holzer, P., and Lippe, L.T. 1988. Stimulation of afferent nerve endings by intragastric capsaicin protects against ethanol-induced damage of gastric mucosa. Neuroscience. 27:981-987.

33. Ekblad, E., Mei, Q., and Sundler, F. 2000. Innervation of the gastric mucosa. Microsc. Res. Tech. 48:241-257.

34. Cocks, T.M., and Moffatt, J.D. 2000. Protease-activated receptors: sentries for inflammation? Trends Pharmacol. Sci. 21:103-108.

35. Shintani, Y., Hirano, K., Nishimura, J., and Kanaide, H. 2000. Trypsininduced contraction was not mediated by the protease-activated receptor 2 in rat myometrium. Jpn. J. Pharmacol. 82(Suppl.):258P. (Abstr.)

36. Tache, Y., et al. 1984. Calcitonin gene-related peptide: potent peripheral inhibitor of gastric acid secretion in rats and dogs. Gastroenterology. 87:344-349.

37. Matsumoto, J., Takeuchi, K., Ueshima, K., and Okabe, S. 1992. Role of capsaicin-sensitive afferent neurons in mucosal blood flow response of rat stomach induced by mild irritants. Dig. Dis. Sci. 37:1336-1344.

38. Ichikawa, T., et al. 2000. CGRP modulates mucin synthesis in surface mucus cells of rat gastric oxyntic mucosa. Am. J. Physiol. Gastroinvest. Liver Physiol. 279:G82-G89.

39. Takeda, Y., and Krause, J.E. 1989. Neuropeptide K potently stimulates salivary gland secretion and potentiates substance P-induced salivation. Proc. Natl. Acad. Sci. USA. 86:392-396.

40. Camerer, E., Huang, W., and Coughlin, S.R. 2000. Tissue factor- and factor $\mathrm{X}$-dependent activation of protease-activated receptor 2 by factor VIIa. Proc. Natl. Acad. Sci. USA. 97:5255-5260.

41. Kawabata, A., et al. 2001. Factor Xa-evoked relaxation in rat aorta: involvement of PAR-2. Biochem. Biophys. Res. Commun. In press.

42. Koshikawa, N., et al. 1998. Expression of trypsin by epithelial cells of various tissues, leukocytes, and neurons in human and mouse. Am. J. Pathol. 153:937-944. 